\title{
Correction to: Laboratory investigation of coupled electrical interaction of fracturing rock with gases
}

Yuji Enomoto ${ }^{1^{*}} \mathbb{0}$, Tsuneaki Yamabe ${ }^{1}$, Shigeki Sugiura ${ }^{2}$ and Hitoshi Kondo ${ }^{2}$

Correction to: Earth, Planets and Space (2021) 73:90 https://doi.org/10.1186/s40623-021-01416-1

Following publication of the original article (Enomoto et al. 2021), the authors reported an error in the number notation on the abscissa in Fig. 3e.

The sampling period for the measurement in Fig. $3 \mathrm{e}$ is $0.167 \mathrm{~min}$, but not $1.6 \mathrm{~min}$.
The corrected Fig. 3 is provided in this Correction.

The original article (Enomoto et al. 2021) has been updated.

1 Shinshu University, Ueda Campus, 3-15-1 Tokida, Ueda, Nagano

Full list of author information is available at the end of the article 

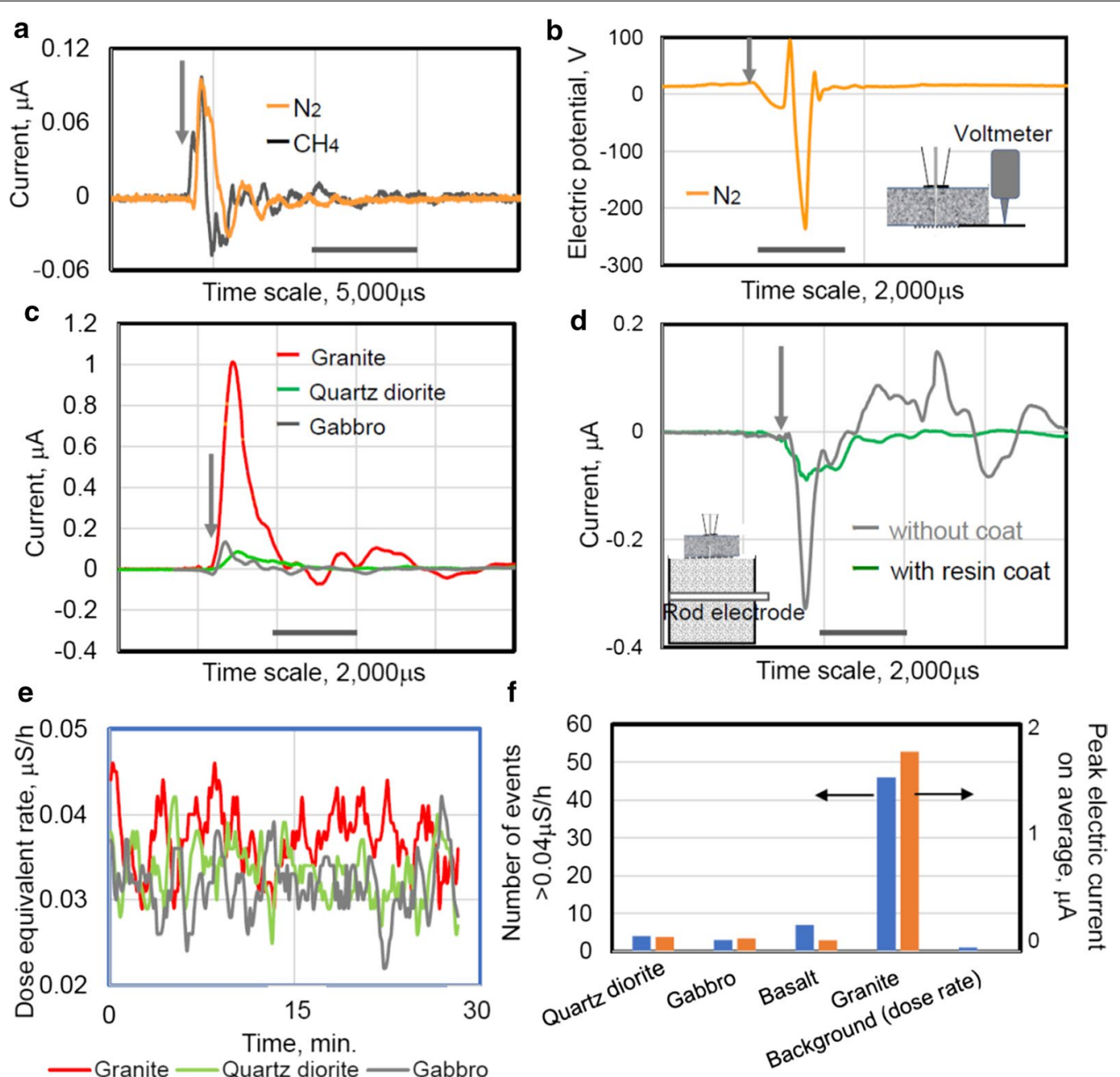

Fig. 3 a and $\mathbf{b}$ Typical results for third series of experiments. a Currents for combination of gabbro/ $\mathrm{CH}_{4}$ or $\mathrm{N}_{2}$ at $\sim 160{ }^{\circ} \mathrm{C}$, which are enlarged the signals in the middle of Fig. 2e; $\mathbf{b}$ electric potential for gabbro $/ \mathrm{N}_{2}$ at $\sim 160^{\circ} \mathrm{C}$. $\mathbf{c}$ and $\mathbf{d}$ Typical results for fourth series of experiments. $\mathbf{c}$ Current and vibration for combination of granite/ $/ \mathrm{CO}_{2}$ at $\sim 25^{\circ} \mathrm{C}$ and $\mathbf{d}$ induced current signals at the pipe electrode with and without non-conductive resin coating buried in a container filled with granite grains and soil. Arrows show in $\mathbf{a}-\mathbf{d}$ the final rupture point when the gas started to flow in the crack gap. e Gamma-ray equivalent dose rate for granite, gabbro, and quartz diorite in 30-min measurements. $\mathbf{f}$ Comparison number $\mathrm{NY}_{>0.04}$ of events for the $\mathrm{\gamma}$-ray equivalent dose rate greater than $0.04 \mathrm{\mu Sv} / \mathrm{h}$ and average peak currents for several test runs of quartz diorite, gabbro, basalt, and granite with $\mathrm{CO}_{2}$ at $\mathrm{S}=1.2 \times 10^{-4} \mathrm{~m}^{2}$ and $\sim 25^{\circ} \mathrm{C} ; \mathrm{NY}>0.04$ for the background in open air is also included. Arrows pointing to the left and right indicate the vertical axis showing the units of the blue and orange bar graphs

\section{Author details}

${ }^{1}$ Shinshu University, Ueda Campus, 3-15-1 Tokida, Ueda, Nagano 386-8567, Japan. ${ }^{2}$ Genesis Research Institute, Inc, 4-1-35 Noritake-Shinmachi, Nishi-ku, Nagoya, Aichi 451-0051, Japan.

Published online: 23 July 2021

\section{Publisher's Note}

Springer Nature remains neutral with regard to jurisdictional claims in published maps and institutional affiliations.

\section{Reference}

Enomoto Y, Yamabe T, Sugiura S, Kondo H et al (2021) Laboratory investigation of coupled electrical interaction of fracturing rock with gases. Earth Planets Space 73:90. https://doi.org/10.1186/s40623-021-01416-1 